\title{
PELATIHAN APLIKASI SPSS UNTUK PEMECAHAN MASALAH PERHITUNGAN PADA STATISTIKA DESKRIPTIF DI SMA NEGERI 1 MALUKU TENGAH
}

\author{
Muhammad Yahya Matdoan ${ }^{*}$, Muhidin Jariyah ${ }^{2}$, Irfandy Walli ${ }^{3}$ \\ 1,2'3 Universitas Pattimura, Ambon, Indonesia \\ *Penulis Koresponsensi, email: keepyahya@gmail.com
}

\begin{abstract}
Statistics is a very difficult material, especially in the process of calculating and analyzing data which tends to be complicated because it requires accuracy and accuracy in its calculations. However, along with the rapid advancement in technology, various computer applications that are specifically designed to help calculate statistical data have emerged, one of which is SPSS. The method of activities held in community service (PKM) is in the form of SPSS training. Participants in this activity were students of SMA Negeri 1 Maluku Tengah. The conclusion obtained in this service is the results of the evaluation given at the end of the activity, of the 28 training participants, all students who took part in the training were able to complete the assigned tasks very well. In addition, teachers must equip students with programming skills, especially statistical and mathematical applications, so that they can arouse students' enthusiasm and interest in learning mathematics and statistics. The necessary follow-up is that it is necessary to carry out further training to hone the interests and abilities of teachers more deeply.
\end{abstract}

Keywords: Students, Statistics, SPSS

\begin{abstract}
Abstrak. Statistika merupakan materi yang sangat sulit, terutama pada proses perhitungan dan analisis data yang cenderung rumit karena memerlukan ketelitian serta kecermatan dalam perhitungannya. Namun seiring dengan kemajuan yang pesat dalam bidang teknologi, muncul berbagai aplikasi komputer yang dirancang khusus untuk membantu perhitungan data statistik salah satunya adalah SPSS. Metode kegiatan yang diadakan dalam pengabdian kepada masyarakat (PKM) ini berupa pelatihan SPSS. Peserta dalam kegiatan ini yaitu siswa-siswi SMA Negeri 1 Maluku Tengah. Kesimpulan yang diperoleh dalam pengabdian ini yaitu hasil evaluasi yang diberikan pada akhir kegiatan, dari 28 orang peserta pelatihan terdapat semua siswa yang mengikuti pelatihan mampu menyelesaikan tugas yang diberikan dengan sangat baik. Selain itu, para guru harus membekali siswa dengan kemampuan pemograman terlebih khusus aplikasi statistik maupun matematika, sehingga dapat membangkitkan semangat dan minat siswa dalam mempelajari pelajaran matematika dan statistika. Tindaklanjut yang diperlukan yaitu perlu dilakukan pelatihan lanjutan untuk mengasah minat dan kemampuan guru dengan lebih dalam.
\end{abstract}

Kata Kunci: Siswa, Statistik, SPSS

How to Cite: Matdoan, M.Y., Jariyah, M., \& Walli, I. (2021). Pelatihan Aplikasi SPSS untuk Pemecahan Masalah Perhitungan pada Statistika Deskriptif di SMA Negeri 1 Maluku Tengah. Mitra Mahajana: Jurnal Pengabdian Masyarakat,2(2), 145-151. https://doi.org/10.37478/mahajana.v2i2.897

\section{PENDAHULUAN}

Statistika merupakan salah satu materi yang penuh dengan data, rumus dan grafik sehingga banyak pihak mengatakan bahwa statistika merupakan pelajaran yang sulit terutama untuk siswa/siswi tingkat SMA. Selain rumus-rumus yang banyak dan sulit untuk diingat, menurut sebagian siswa/i, statistika juga memiliki hitungan yang rumit dan grafik serta memerlukan asumsi yang cukup banyak (Rahmalina, 2018).

Pemecahan masalah dalam statistika merupakan sebuah kemampuan kognitif fundamental yang dapat dilatih dan dikembangkan pada siswa, sehingga diharapkan ketika siswa mampu memecahkan masalah statistika dengan baik maka akan mampu menyelesaikan masalah nyata paskah menempuh pendidikan formal (Amam, 2017).

Berdasarkan pengalaman dan pengamatan, bahwa sebagian siswa berpendapat bahwa melakukan perhitungan dan statistika sangat sulit, terutama pada proses analisis data yang cenderung rumit dan memerlukan ketelitian serta kecermatan dalam perhitungannya. Namun seiring dengan kemajuan yang pesat dalam bidang teknologi, muncul berbagai aplikasi 
komputer yang dirancang khusus untuk membantu perhitungan data statistik (Efendi, 2021). Perhitungan data statistik menjadi jauh lebih mudah dan menyenangkan tanpa mengurangi ketepatan dalam perhitungan (Santoso, 2019).

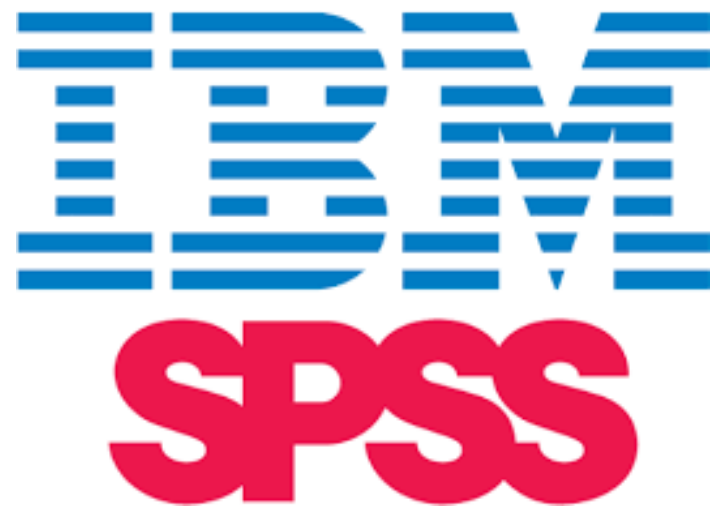

\section{Gambar 1. Logo Aplikasi SPSS}

Salah satu software yang bisa digunakan untuk mengolah data dan menganalisis data yaitu SPSS (Statistical Package for the Social Sciences). SPSS digunakan khusus untuk menghitung dan pengolahan data statistik yang paling populer serta paling banyak digunakan di seluruh dunia. SPSS dipakai dalam berbagai riset pasar, pengendalian dan perbaikan mutu (quality improvement), serta riset-riset sains (Yudha \& Rahmad, 2020). Dilihat dari fungsinya, SPSS digunakan dalam pengolahan dan analisis data kuantitatif, karena saling berhubungan dan juga termasuk dalam ruang lingkup statistik. Awalnya SPSS dibuat untuk keperluan pengolahan data statistik untuk ilmu ilmu sosial, sehingga SPSS merupakan singkatan dari Statistical Package for the Social Sciences. Sesuai dengan perkembangan jaman, saat ini kemampuan SPSS diperluas untuk melayani berbagai jenis pengguna (user), seperti untuk proses produksi di pabrik, riset ilmu sains, dan lain-lain. Dengan demikian, kepanjangan dari SPSS dirubah menjadi Statistical Product and Service Solutions (Pramesti, 2016).

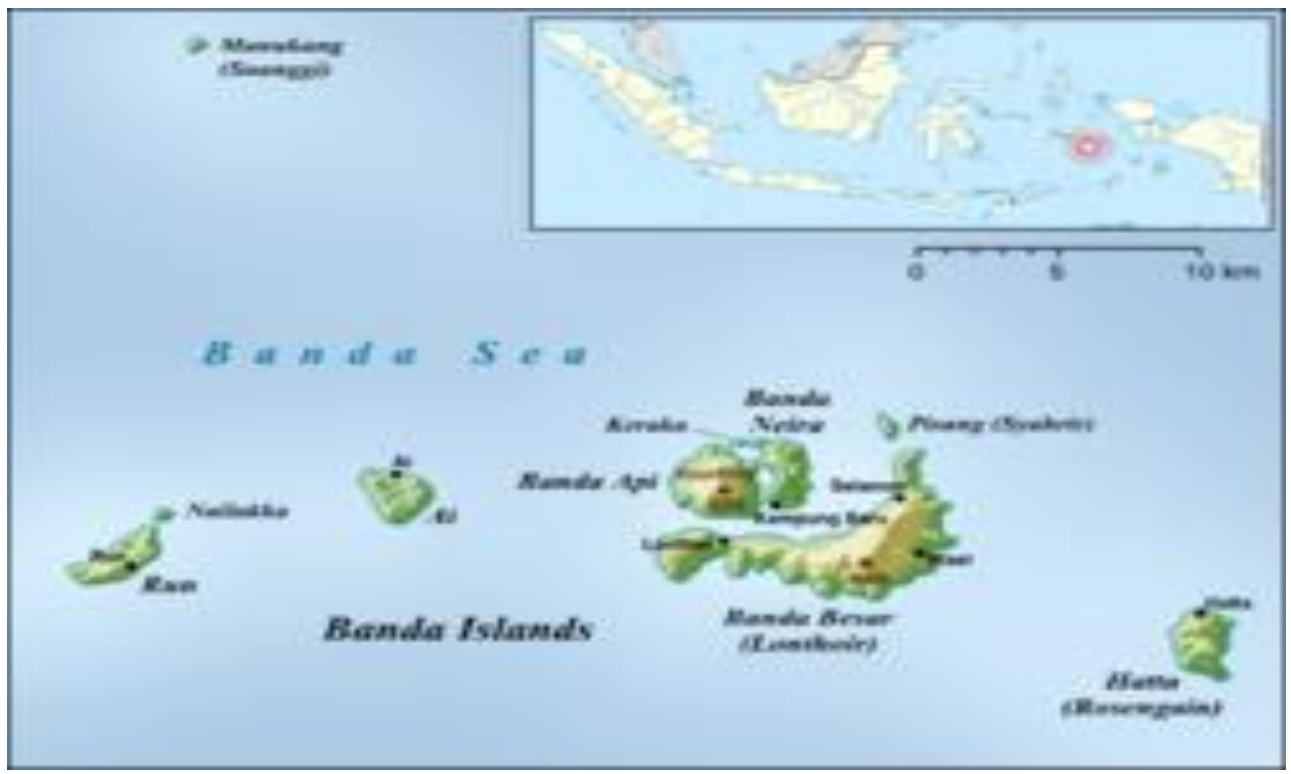

Gambar 2. Peta Lokasi Pengabdian 


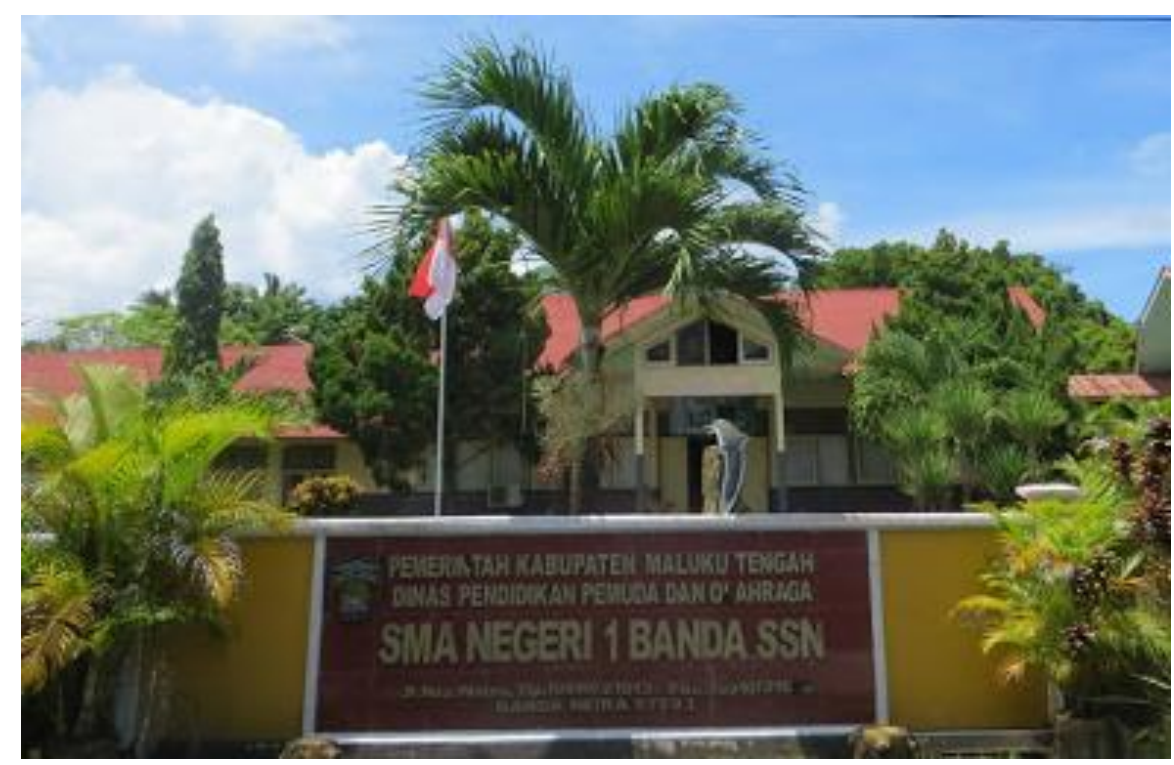

Gambar 3. SMA Negeri 1 Maluku Tengah

SMA Negeri 1 Maluku Tengah merupakan SMA yang terletak di Kecamatan Banda Kabupaten Maluku Tengah. Letak SMA ini dapat dikatakan jauh dari Kota Ambon sebagai ibu kota Provinsi Maluku. Dalam pembelajaran statistika di SMA Negeri 1 Maluku Tengah masih menggunakan metode perhitungan secara manual (tanpa menggunakan aplikasi statistik). Oleh karena itu, perlu adanya pelatihan aplikasi SPSS untuk melakukan perhitungan statistika deskriptif. Tujuan dan manfaat dan dari kegiatan pelatihan ini diharapkan agar para siswa dapat mengetahui dan mengusai aplikasi statistik khsusnya SPSS sera dapat membuat para siswa lebih semangat dan tertarik untuk belajar pelajaran statistika serta matematika secara umum dan diharapkan agar para siswa menerapkanya dalam setiap pembelajaran.

\section{METODE PELAKSANAAN}

Metode kegiatan yang diadakan dalam pengabdian masyarakat (PKM) ini berupa pelatihan SPSS. Peserta dalam kegiatan ini yaitu siswa-siswi SMA Negeri 1 Maluku Tengah. Pelatihan ini dilaksanakan pada 31 januari 2020 dengan tahap-tahapanya meliputi:

1. Peserta menempati ruangan

2. Sambutan dan pembukaan kegiatan oleh Kepala SMA Negeri 1 Maluku Tengah

3. Sambutan dari Koordinator PKM

4. Tim memberikan materi tentang konsep-konsep statistik, serta teknik perhitungan statistik deskriptif. Materi statitika yang dibahas dalam pelatihan ini yaitu berupa statistik deskriptif yang terdiri perhitungan mean, media, modus, simpangan rata-rata, simpangan baku, desil, persentil, quartil, kurtosis, skewness dan penyajian data dalam tabel distribusi tabel frekuensi, diagram batang, diagram garis dan ogive.

5. Pelatihan penggunaan aplikasi SPSS.

Pelatihan yang dilakukan di SMA Negeri 1 Maluku Tengah menggunakan aplikasi SPSS 25 , yang di sudah dipasang pada setiap komputer maupun leptop yang digunakan peserta dalam pelatihan.

6. Evaluasi kegiatan dilaksanakan selama pelatihan, baik di awal maupun akhir pelatihan. guna mengevalusasi aspek capaian dari tujuan dilakukan pelatihan dan keberhasilan dari penyelenggaraan kegiatan. 


\section{HASIL DAN PEMBAHASAN}

Kegiatan pengabdian yang dilakukan berjudul "Pelatihan Aplikasi SPSS Untuk menyelesaikan permasalahan matematika yang semakin kompleks". Dilakukan dengan cara tatap muka yang diselanggarakan di SMA Negeri 1 Maluku Tengah pada hari Rabu, tanggal 31 januari 2020. Adapun nama-nama siswa dan guru yang hadir dalam pelatihan ini yaitu terdiri dari siswa/i dan guru matematika di SMA Negeri 1 Maluku Tengah yang berjumlah 28 peserta.

Tabel 1. Daftar Peserta Pelatihan

\begin{tabular}{clc}
\hline Nomor & \multicolumn{1}{c}{ Nama } & Keterangan \\
\hline 1. & Aryo Sapto & Siswa \\
2. & Salma Sari & Siswa \\
3. & Muthmainna & Siswa \\
4. & Nafisa & Siswa \\
5. & Fatima & Siswa \\
6. & Rasyid & Siswa \\
7. & Saban Radjid & Siswa \\
8. & Rudi Masrun & Siswa \\
9. & Siti Ubaya & Siswa \\
10. & La Panda Yudi & Siswa \\
11. & Samsudi Hato & Siswa \\
12. & Rury saban & Siswa \\
13. & Wa Muriati & Siswa \\
14. & Wa Nita Rina & Siswa \\
15. & Sudirman Rasyid & Siswa \\
16. & Harun Sulaiman & Siswa \\
17. & Sartika Nero & Siswa \\
18. & Ramli Masmuna & Siswa \\
19. & Intan Jubaedah & Siswa \\
20. & Wa Muna & Siswa \\
21. & Laila Sari & Siswa \\
22. & Nur Amaliah & Siswa \\
23. & Heri Masmuki & Siswa \\
24. & La Imran & Siswa \\
25. & La Amir & Siswa \\
26. & Rima Hari & Siswa \\
27. & Wa Muna Juriyah & Siswa \\
28. & Nur Awaliyah & Guru \\
\hline & &
\end{tabular}

Pelaksanaan kegiatan pengabdian masyarakat dilaksanakan selama 1 hari yaitu pada tanggal 31 januari 2020. Kegiatan ini dimulai sambutan dari kepala sekolah SMA Negeri 1 Maluku Tengah. Dalam sambutanya beliau menyampaikan terima kasih yang sebesar-besarnya kepada tim PKM atas pelatihan yang dilakukan terhadap siswa-siswi SMA Negeri 1 Maluku Tengah. Selanjutnya sambutan dari Koordinator Tim pengabdian Kepada Masyarakat (PKM) Muhammad Yahya Matdoan, dalam sambutanya beliau menyampaikan bahwa Kecamatan Banda merupakan daerah yang sangat indah dan kaya akan rempah-rempah terutama pala. selain itu banda juga merupakan tempat pengasingan tokoh bangsa Indonesia yaitu Bung Karno 
dan Bung Syahrir dan memiliki banyak tempat bersejarah. Selain itu, beliau menyampaikan bahwa peran dan pentingnya siswa dalam mengusai ilmu statistika maupun matematika dalam menghadapi persaingan global di era sekarang ini.

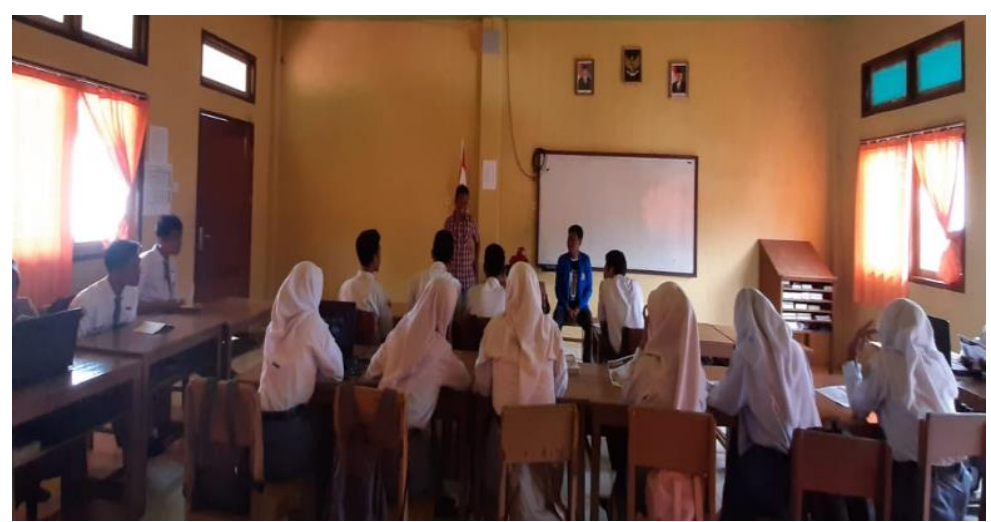

Gambar 1. Koordinator PKM memberikan Sambutan

Selanjutnya pada sesi ke dua dimulai dengan materi konsep matematika dan statistika yang disampaikan oleh Muhammad Yahya Matdoan selaku Koordinator PKM. Kemudian dilanjutkan dengan sosialisasi Program Studi Statistika dan Matematika FMIPA Universitas Pattimura.

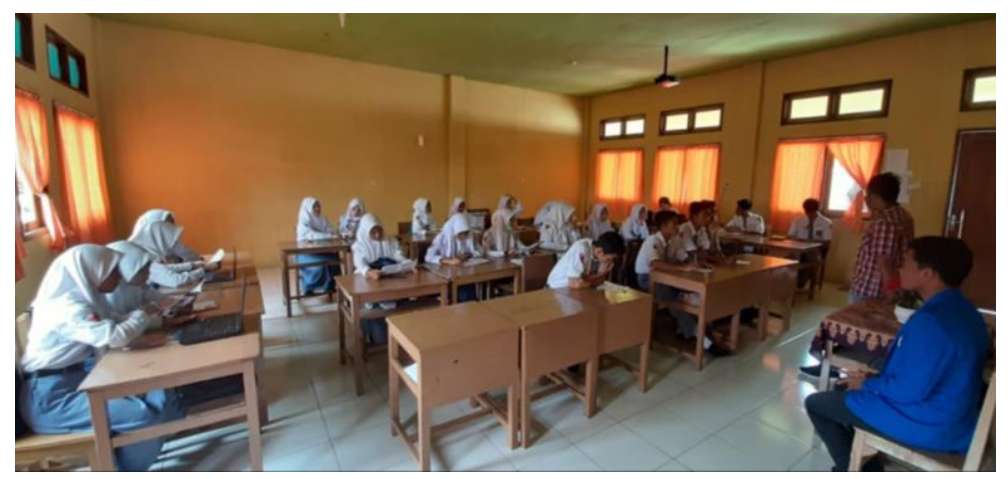

Gambar 2. Suasana pelatihan yang disampaikan oleh M. Yahya Matdoan

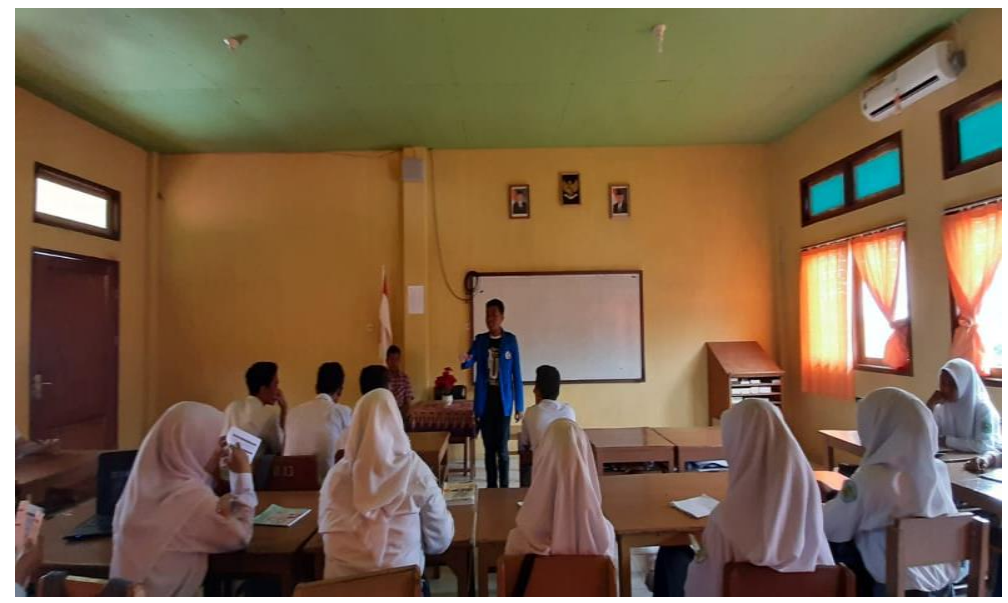

Gambar 3. Suasana Workshop yang diikuti oleh siswa-siswi 


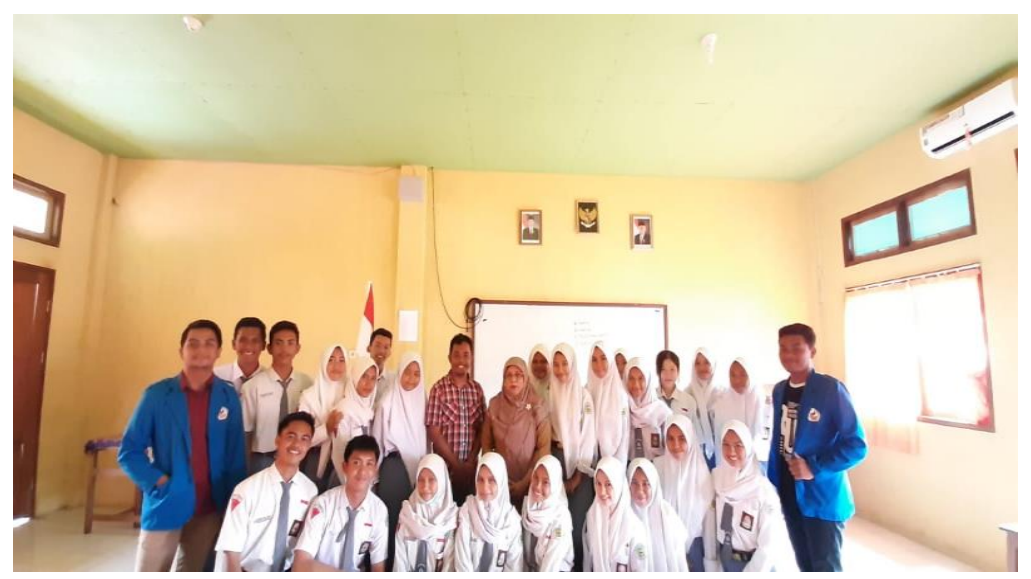

Gambar 4. Foto Bersama Peserta Pelatihan

Hasil pelaksanaan kegiatan pengabdian secara keseluruhan dapat dilihat berdasarkan beberapa komponen berikut ini:

1. Ketercapaian target jumlah peserta pelatihan.

Target peserta pelatihan atau khalayak sasaran adalah 30 siswa SMA Negeri 1 Maluku Tengah yang tergabung dalam kelas IPA. Dalam pelaksanaannya kegiatan ini diikuti oleah 28 siswa karena ada beberapa yang tidak hadir. Dengan demikian ketercapaian target jumlah peserta pelatihan adalah $99,06 \%$ atau dapat dinilai baik.

2. Ketercapaian tujuan pelatihan.

Ketercapaian tujuan pelatihan dapat dinilai sangat baik. Dalam kurun dua jam para siswa yang mengikuti pelatihan sudah mengusai pemcahan masalah statistika deskriptif dengan menggunakan SPPS.

3. Ketercapaian target materi yang telah direncanakan.

Ketercapaian target materi yang telah direncanakan pada kegiatan pengabdian ini dapat dinilai baik (85\%). Semua materi yang telah direncanakan dapat disampaikan kepada peserta, meskipun karena keterbatasan waktu ada beberapa materi yang hanya disampaikan secara garis besar. Kemampuan peserta dalam penguasaan materi Kemampuan peserta dilihat dari penguasaan materi dapat dinilai baik (90\%). Hal ini dapat dilihat dari kemampuan siswa-siswi dalam kegiatan pelatihan dan praktik berupa pemecahan masalah perhitungan statistik deskriptif dengan cara manual kemudian dilakukan dengan menggunakan aplikasi SPSS. Selain itu, antusiasme siswa dalam pelatihan berlangsung memberikan beberapa pertanyaan. Selanjutnya peserta pelatihan diberikan latihan terkait dengan pelatihan yang telah dilakukan. Diperoleh hasil bahwa semua peserta mampu menyelesaikan tugas yang diberikan. Oleh sebab itu, diharapkan peserta pelatihan dapat memanfaatkan pengetahuan ini untuk mampu mengembangkan diri dalam pembelajaran di kelas sehingga menarik siswa untuk terus belajar matematika dan statistika.

\section{SIMPULAN DAN TINDAK LANJUT}

Berdasarkan kegiatan pengabdian masyarakat yang telah dilaksanakan pada SMA Negeri 1 Maluku Tengah, terdapat beberapa hal yang dapat dijadikan sebagai kesimpulan yaitu:

1. Pengabdian Kepada Masyarakat yang dilakukan oleh Tim PKM Program Studi Statistika FMIPA Unpatti dengan menggunakan metode ceramah dan pratikum telah mampu 
meningkatkan pemahaman siswa-siswi pada SMA Negeri 1 Maluku Tengah dan diharapkan para siswa terus mengembangkan ilmu yang diperoleh.

2. Berdasarkan hasil evaluasi yang diberikan pada akhir kegiatan, dari 28 orang peserta pelatihan terdapat semua peserta yang mengikuti pelatihan mampu menyelesaikan tugas yang diberikan dengan sangat baik.

3. Para guru harus membekali siswa dengan kemampuan pemograman terlebih khusus aplikasi statistik maupun matematika, sehingga dapat membangkitkan semangat dan minat siswa dalam mempelajari pelajaran matematika dan statistika.

4. Pihak Sekolah harus menambah fasilitas komputasi agar menunjang kegiatan pratikum bagi siswa. Selain itu pihak sekolah harus mengikuti perkembangan teknologi informasi agar dapat diterapkan atau diajarkan kepada para siswa.

5. Tindaklanjut yang diperlukan yaitu perlu dilakukan pelatihan lanjutan untuk mengasah minat dan kemampuan guru dengan lebih dalam.

\section{DAFTAR PUSTAKA}

Amam, A. (2017). Penilaian kemampuan pemecahan masalah matematis siswa SMP. Teorema: Teori dan Riset Matematika, 2(1), 39-46.

Efendi, Y., Lusiana, L., Muzawi, R., Yanti, R., \& Imardi, S. (2021). WORKSHOP E-LEARNING GOOGLE CLASSROOM DAN VIDEO PEMBELAJARAN PADA SMP N 35 PEKANBARU. Mitra Mahajana: Jurnal Pengabdian Masyarakat, 2(1), 82-89.

Pramesti, G. (2016). Statistika lengkap secara teori dan aplikasi dengan SPSS 23. Elex Media Komputindo.

Rahmalina, W., Jusman, Y., \& Salamun, S. (2018). Pelatihan Aplikasi Maple pada Mata Pelajaran Matematika. Jurnal Pengabdian Masyarakat Multidisiplin, 1(3), 243-253.

Ramadhani, R., \& Sribina, N. (2019). Pemanfaatan Media Pembelajaran SPSS untuk Meningkatkan Kemampuan Statistik Siswa SMK. Jurnal Solma, 8(1), 159-170.

Santoso, S. (2019). Menguasai SPSS versi 25. Jakarta: Elex Media Komputindo.

Yudha, C. B., \& Rahmad, I. N. (2020). PELATIHAN PENULISAAN PENELITIAN TINDAKAN KELAS (PTK) PADA GURU SDN CIBITUNG KULON 01 BOGOR. Mitra Mahajana: Jurnal Pengabdian Masyarakat, 1(1), 20-23. 